\title{
VARIAÇÕES FORMAIS EM UM SISTEMA GENERATIVO: O SINTAGMA COMO HIPÓTESE DE CONTROLE SEMÂNTICO
}

\author{
FORMAL VARIATIONS IN A GENERATIVE SYSTEM: SINTAGM AS A HYPOTHESIS FOR \\ SEMANTIC CONTROL
}

\author{
Pedro Engel ${ }^{1}$
}

\section{RESUMO:}

A definição dos meios para controlar o processo generativo em um sistema computacional que aspira automação em projeto depende de como entendemos e organizamos as informações codificadas no programa. Trata-se de um problema que deve ser considerado à luz de questões contingentes, como propósito e tipo de usuário. Vinculado a uma estratégia de pesquisa pelo projeto, este artigo aborda a elaboração de uma definição de Rhinoceros/ Grasshopper como apoio ao ensino de projeto ilustrando as relações entre elementos de fachada em edifícios de estrutura independente. O processo generativo produz variações compositivas por meio da seleção e deslocamentos de elementos arquitetônicos. O desenvolvimento do módulo de controle do algoritmo implica em considerar o principal propósito pedagógico deste projeto: promover compreensão da manipulação formal ressaltando o vínculo entre operações sintáticas e a dimensão semântica da arquitetura. Será apresentada hipótese para endereçar este problema: uma reorganização do módulo de controle aprimorando um sistema de filtros desenvolvido anteriormente. Seguindo princípios da Linguagem dos Padrões, de Alexander et al. (1977), buscou-se contornar o problema do tratamento independente das variáveis aproximando precedentes arquitetônicos onde a combinação elementos atua em conjunto criando respostas coerentes a problemas de projeto com demandas múltiplas e conflitantes. A modalidade, denominada "controle por sintagma" - conceito da linguística que se refere a conjunto de palavras ordenado segundo regras sintáticas - busca controlar variações usando padrões combinatórios prédefinidos com base nos precedentes estudados.

PALAVRAS-CHAVE: tecnologias de projeto; ensino de projeto; computação; Linguagem de Padrões.

\section{ABSTRACT:}

To define the means of control for generative process in a computer system that aspires design automation depends on how we understand and organize the information encoded in the program. This key aspect must be considered in the light of contingent issues, such as purpose and the understanding of who will operate it. As part of a research by design strategy, this article addresses a Rhinoceros / Grasshopper definition whose purpose is to aid a basic design course illustrating the syntactic relations of facade elements in infill architecture. The generative process produces variations in the composition through the selection and displacements of architectural elements. The development of the control module implies considering the main pedagogical purpose of this project: to promote an understanding of formal manipulation that emphasizes the link between syntactic operations and the semantic dimension of architectural form. A hypothesis will be presented to address this problem: a reorganization of the control module based on the improvement of a filter system previously developed. Following logical principles of A Patterns Language, by Alexander et al. (1977), we tried to circumvent the problem of independent treatment of variables with the approximation of architectural precedents where elements act together to provide a coherent response to design problems with multiple and sometimes conflicting demands. The new modality is called "syntagmatic control" - a concept of linguistics that refers to a set of words ordered according to syntactic rules - and seeks to allow controlling variations in classes of elements using predefined combinatorial patterns based on the precedents studied.

KEYWORDS: design technology; design teaching; computation; Pattern Language.

How to cite this article:

ENGEL, P. Variações formais em um sistema generativo: o sintagma como hipótese de controle semântico. Gestão \& Tecnologia de Projetos. São Carlos, v17, n1, 2022. https://doi.org/10.11606/gtp.v17i1.183945
${ }^{1}$ Universidade federal do Rio de Janeiro. Programa de Pós-Graduação em Urbanismo.

Fonte de Financiamento:

CNPq. Processo:

439022/2018-5.

Conflito de Interesse:

Declara não haver.

Ética em Pesquisa:

Declara não haver

necessidade.

Submetido em: 07/04/2021 Aceito em: 05/08/2021 


\section{INTRODUÇÃO}

Em qualquer sistema computacional que aspira algum grau de automação em projeto, um aspecto fundamental é a escolha dos meios para controlar o processo generativo. Entre as questões implicadas, duas merecem destaque: primeiramente, a escolha dos parâmetros que devem ser informados ao sistema para realizar a geração de alternativas e, em segundo lugar, o quanto é ofertado ao controle humano e o quanto é operado por algoritmo pré-programado. 0 enfrentamento destas questões suscita reflexões sobre como entendemos e organizamos as informações e ações codificadas no programa. Além disso, é razoável que sejam ponderadas à luz de outras perguntas mais contingentes. Qual o propósito do sistema? Quem deverá operálo? Quais as limitações e possibilidades do seu ambiente digital?

Na experiência relatada neste artigo, o desenvolvimento de aspectos computacionais de um algoritmo é apresentado por meio de ponderações desta natureza. A experiência é considerada uma rica oportunidade para repensar os modos de apresentação do conhecimento arquitetônico e sua participação no processo de ensino da concepção do projeto.

O algoritmo em questão é o Supergrid, desenvolvido nos softwares Rhinoceros/Grasshopper com o objetivo de produzir composições de fachadas e gerar modelos - físicos e digitais - para serem empregados como ferramentas pedagógicas nos primeiros períodos do curso de arquitetura e urbanismo. Em sua fase inicial, o projeto tinha como meta a produção de material didático na forma de modelos físicos que seriam usados em sala de aula para apresentar aos estudantes possíveis relações entre os elementos das fachadas de projetos organizados a partir da grelha estrutural independente. Este propósito levantava imediatamente a questão de como organizar as diferentes relações formais apresentadas nesse catálogo. No decorrer da pesquisa passou-se a perseguir também a possibilidade de manipulação direta do sistema por estudantes, viabilizando ações pedagógicas de exploração das variações sintáticas. Essa perspectiva tornou premente a questão de como ofertar o controle das variações aos estudantes em ambiente digital.

Ambas as questões foram consideradas tendo em vista uma intenção pedagógica: a de tratar as variações formais a partir do seu sentido arquitetônico, e não apenas a partir de suas características exclusivamente geométricas. A noção de "controlador semântico" deriva justamente da intenção de desenvolver o sistema - e em especial o modo de operá-lo - visando fortalecer a compreensão das variações sintáticas (forma) em termos de suas implicações semânticas (sentido arquitetônico).

Em fases anteriores, o algoritmo previa um modo que permitia diferentes métodos de controle das suas ações, incluindo um modo de total controle do usuário, um modo generativo totalmente aleatório e um modo baseado em filtros na forma de parâmetros quantitativos. Os avanços a serem descritos neste artigo focam no desenvolvimento de um novo modo de controle das variações do sistema, baseado na vinculação entre diferentes variáveis por meio de padrões. Recorrendo à lógica da Linguagem dos Padrões, de Christopher Alexander (1977), estabeleceu-se conjuntos de variáveis associadas, tendo como referência o exame de soluções existente no universo de arquiteturas examinadas pela pesquisa. 0 agrupamento de variáveis - que no âmbito deste projeto foram denominados "sintagmas" - tem por propósito fazer com que o sistema seja operado a partir da interrelação entre elementos arquitetônicos levando-se em consideração o potencial desempenho dos elementos atuando em conjunto na mediação entre interior e exterior. 


\section{SUPERGRID COMO FERRAMENTA DIDÁTCA}

O Supergrid é um algoritmo que viabiliza realizar experimentações formais no âmbito da fachada. Sua aplicação original esteve vinculada a uma disciplina do segundo semestre do curso de Arquitetura e Urbanismo da Universidade Federal do Rio de Janeiro, onde se emprega estratégias didáticas baseadas na lógica do kit-de-partes (LOVE, 2003). Trata-se de exercícios curtos, conduzidos principalmente por meio de modelos físicos e desenhos analógicos, em que estudantes operam com um conjunto limitado de elementos distribuídos em sistemas de organização pré-definidos. Em um destes exercícios, como apresentado em publicação prévia (ENGEL e ESKINAZI, 2016), pretende-se que os estudantes exercitem o raciocínio sintático explorando relações de forma e posição entre elementos da fachada pertinentes à estrutura independente, aos planos de vedação ou aos dispositivos de proteção. Estas variações permitem abordar questões arquitetônicas fundamentais da fachada entendida como interface entre o interior e exterior, tais como: permeabilidade visual, vista e privacidade; iluminação natural e obscurecimento; insolação e sombreamento; ventilação e estanqueidade; uso e ocupação do espaço; proporção, composição visual e significado.

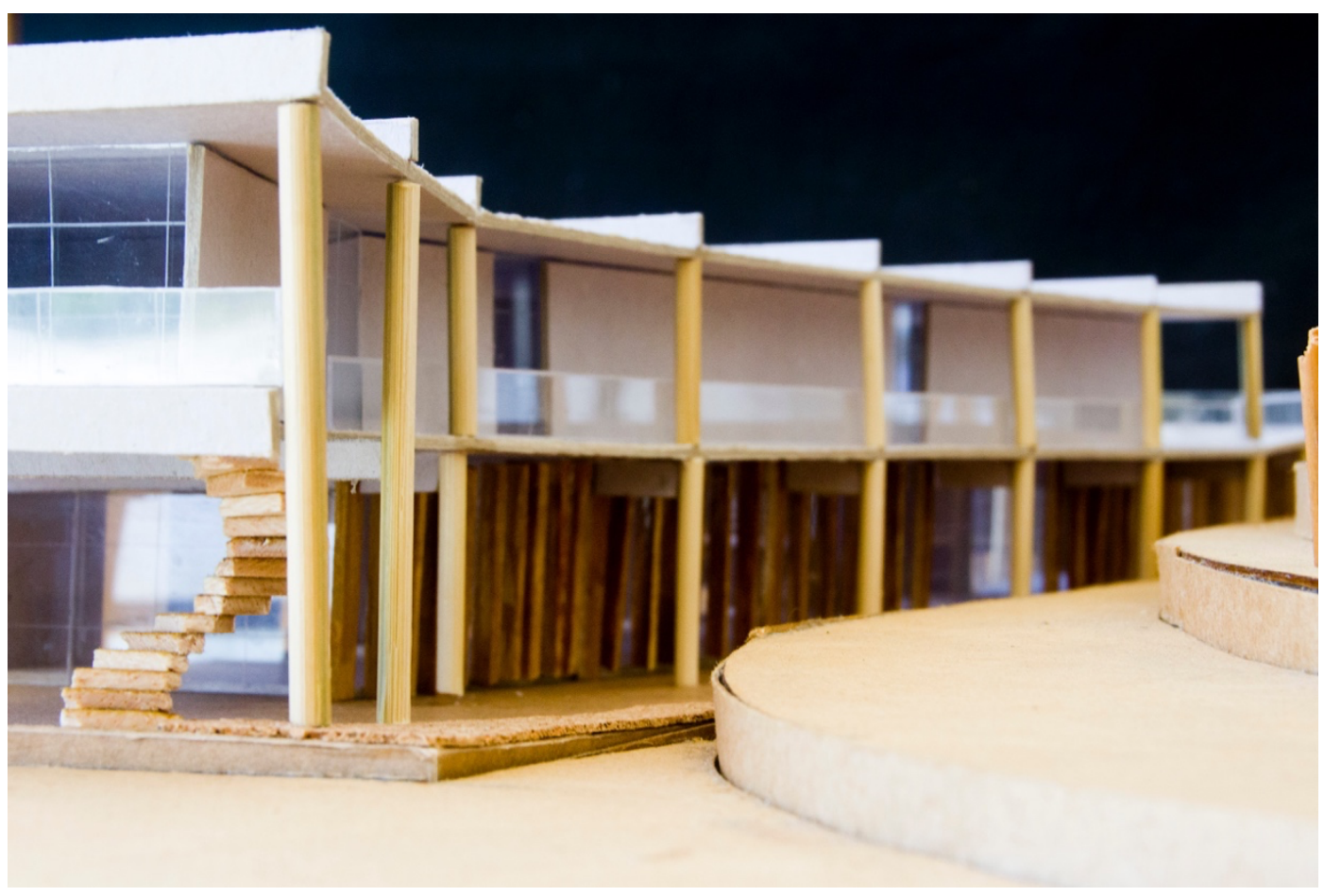

Como parte do material didático foram produzidas maquetes em escala 1:50 que estavam em sala de aula e serviam como apoio nas orientações de projeto. Os modelos possibilitavam aos estudantes e professores visualizar as diversas possibilidades de relações entre elementos da fachada, permitindo discuti-las à luz das questões arquitetônicas mencionadas acima.

O desenvolvimento do Supergrid visava a produção de modelos didáticos em série, possibilitando atender a diferentes turmas e incluindo um número maior de variações e elementos, potencialmente operando como uma espécie de catálogo físico de variações formais em fachadas. 0 sistema foi concebido como uma definição de Rhinoceros/ Grasshopper, empregando o mesmo universo de regras formais que o exercício: estrutura independente organizada em grelha, planos de vedação e elementos de proteção, todos passíveis de variações de posição e forma. Visando a produção de modelos físicos, a definição gerava desenhos em
Figura 1. Projeto do ateliê de Concepção da Forma Arquitetônica 2. Estudante Isabela Lages.

Fonte: Foto do autor. 
linha para o corte a laser de todas as partes. Também foi desenvolvido um sistema de encaixes que permitem uma montagem rápida e fácil, além do bom acabamento do modelo.

Figura 2. Sistema de montagem dos modelos físicos gerados a partir do algoritmo.

Fonte: Foto do autor.

Figura 3 e 4. Sistema de encaixe do modelos físico a partir da fabricação digital e modelos finalizado.

Fonte: Fotos do autor.
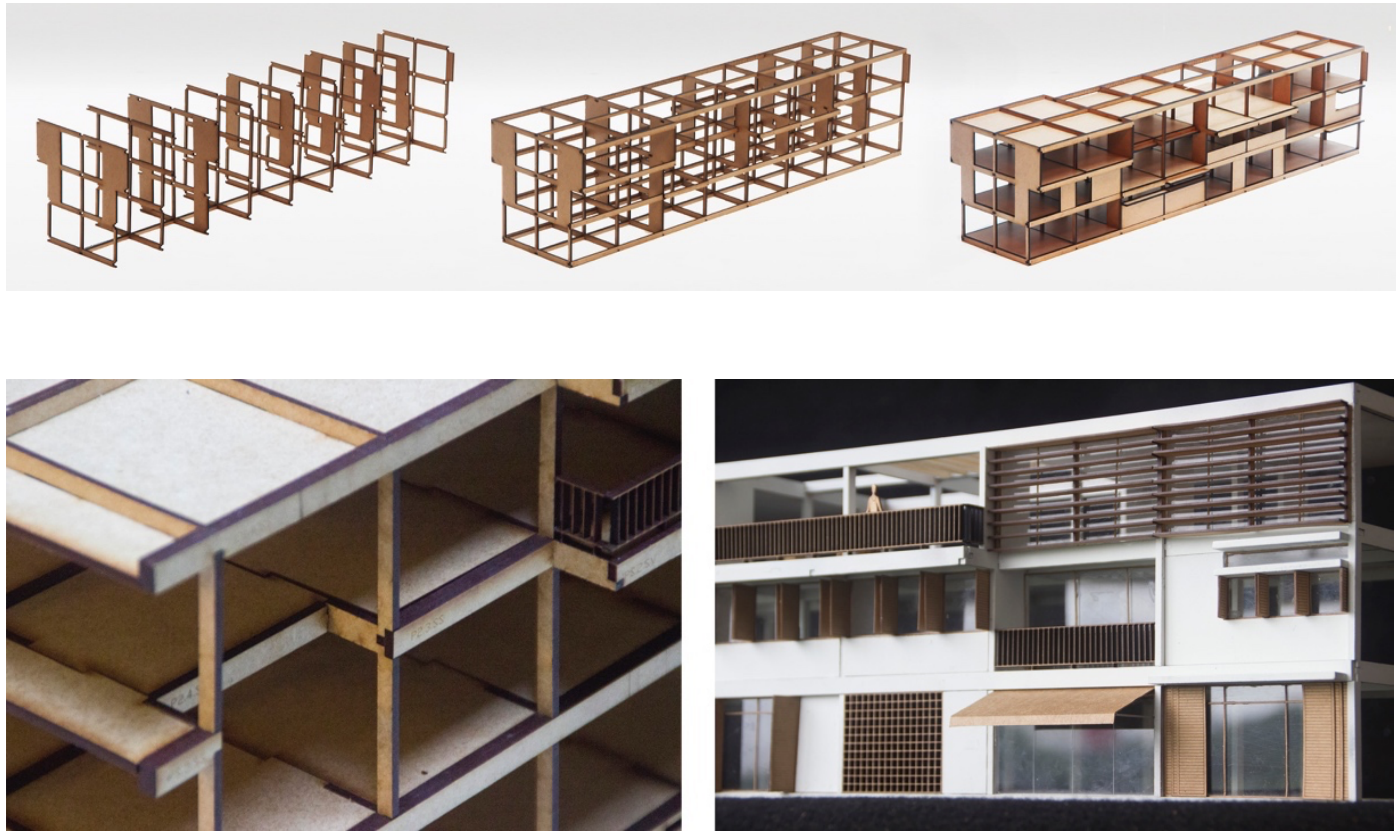

Tal aplicação, antes de sua implementação final, foi inviabilizada pela emergência da pandemia de 2020, levando o projeto a incorporar uma meta complementar: permitir o manejo do Supergrid pelos estudantes em ambiente digital. Essa inflexão coloca uma nova perspectiva sobre o desenvolvimento do algoritmo. Ofertar o comando das variações ao estudante se revela uma oportunidade de conceber módulo de controle ele próprio com ferramenta pedagógica.

\section{PESQUISA POR PROJETO}

Para além da aplicação prática descrita acima, o Supergrid também é uma oportunidade para fazer pesquisa por projeto - research by design - por meio da exploração das possibilidades computacionais relacionadas com sistemas generativos baseados na seleção, combinação e transformação de elementos.

Embora a pesquisa adote princípios presentes na literatura sobre Gramáticas da Forma (STINY, 1977; DUARTE, 2005; BEIRÃO, DUARTE e STOUFFS, 2009; ELOY e DUARTE, 2014; GARCIA, 2016) o trabalho não utiliza seu característico método de aplicação sucessiva de regras, nem explora a capacidade de reconhecimento de figuras emergentes (STINY, 1993; STOUFFS, 2019). A definição computacional desenvolvida aqui é baseada em uma lógica combinatória, em que variações formais resultam da seleção de elementos presentes em bibliotecas e do ajuste de parâmetros que modificam estes elementos.

Não obstante, o sistema segue sendo compreendido conceitualmente como uma espécie de gramática: há elementos, regras formais que guiam a relação entre estes elementos. Como uma espécie de sistema que codifica um domínio de conhecimento, a gramática tem também a capacidade de produzir sentido a partir da combinação e da ordenação dos elementos que a constituem. 0 problema abordado neste artigo trata justamente da questão de como organizamos, apresentamos e operamos com o conhecimento codificado na gramática do Supergrid. Mais especificamente, trata da questão de como governar as variações 
possibilitadas pelo sistema tendo em vista seu propósito pedagógico de ressaltar a ligação entre o raciocínio sintático do manejo da forma e a dimensão semântica do sentido arquitetônico.

\section{ALGORITMO: LÓGICA + CONTROLE}

Segundo Kowalsky (1979), um algoritmo é conceitualmente composto por um componente lógico - uma estrutura organizativa que vincula todos os elementos do sistema - e um componente de controle - que orienta as ações a serem realizadas pelo sistema (STOUFFS e HOU, 2018). No Supergrid o componente lógico é composto por classes de elementos arquitetônicos (pilares, vigas, lajes, planos de fechamento, guarda-corpos, etc.), por regras geométricas que guiam as relações formais entre estes elementos e por variações, isto é, pela seleção de elementos e parâmetros que modificam sua posição. 0 componente de controle, por sua vez, é o que define como as variações serão atribuídas às fachadas. Ele oferta aos usuários diferentes modos de controlar o sistema abarcando variados graus de automação.

\section{COMPONENTE LÓGICO}

O componente lógico do Supergrid pode ser entendido como uma base de dados que organiza os elementos em termos geométricos e classificatórios, e que define as variações a que estão sujeitos. 0 ponto de partida é uma malha ortogonal tridimensional que organiza a geometria do conjunto. Essa malha é parametrizada, sendo possível definir o número de vãos e sua proporção, de modo regular ou variante (ver figura 5). As variações formais são atribuídas a cada segmento da sua face externa (os segmentos são chamados de "célula", possuindo pontos de referência que funcionam como uma espécie de "endereço" e o espaço entre eles é chamado de "interstício"). Além disso, este plano baliza as variações relativas à posição dos elementos, que podem avançar para fora ou recuar para dentro.
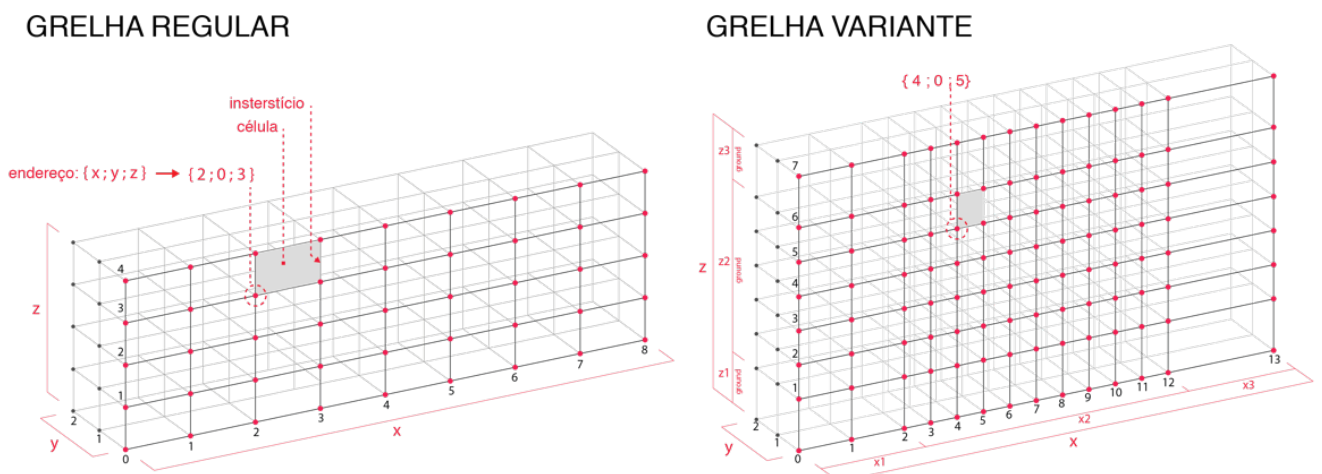

A organização classificatória distribui os elementos arquitetônicos em classes e sub-classes (pilares, vigas, lajes, planos de vedação, elementos de proteção e limites de acesso, por exemplo). Em certas classes os elementos possuem atributos relacionados a suas características formais (proporção entre superfície transparente e opaca, por exemplo). Estes atributos podem ser utilizados como critérios para filtrar a seleção e aplicação de parâmetros. Além disso, algumas classes se configuram como bibliotecas de tipos (por exemplo, a classe proteção solar contém diferentes tipos de brises, toldos, cobogós, planos vazados etc.). As bibliotecas são abertas para que se acrescente mais elementos. 
Figura 6. Diagrama
ilustrando as
diferentes classes de
elementos e as
variações a que estão
sujeitas.
Fonte: Autor. Fonte: Autor.
Finalmente, o componente lógico prevê três modos de variação: posição (deslocamento do elemento em relação ao plano externo da grelha); tipo (seleção do tipo de elemento a partir da biblioteca); e "liga-desliga" (define se determinada classe de elemento está ou não presente em uma determinada célula). Ao todo são 17 tipos de variações, correspondendo a 17 listas que atribuem valores a cada "célula" ou "interstício" da fachada.

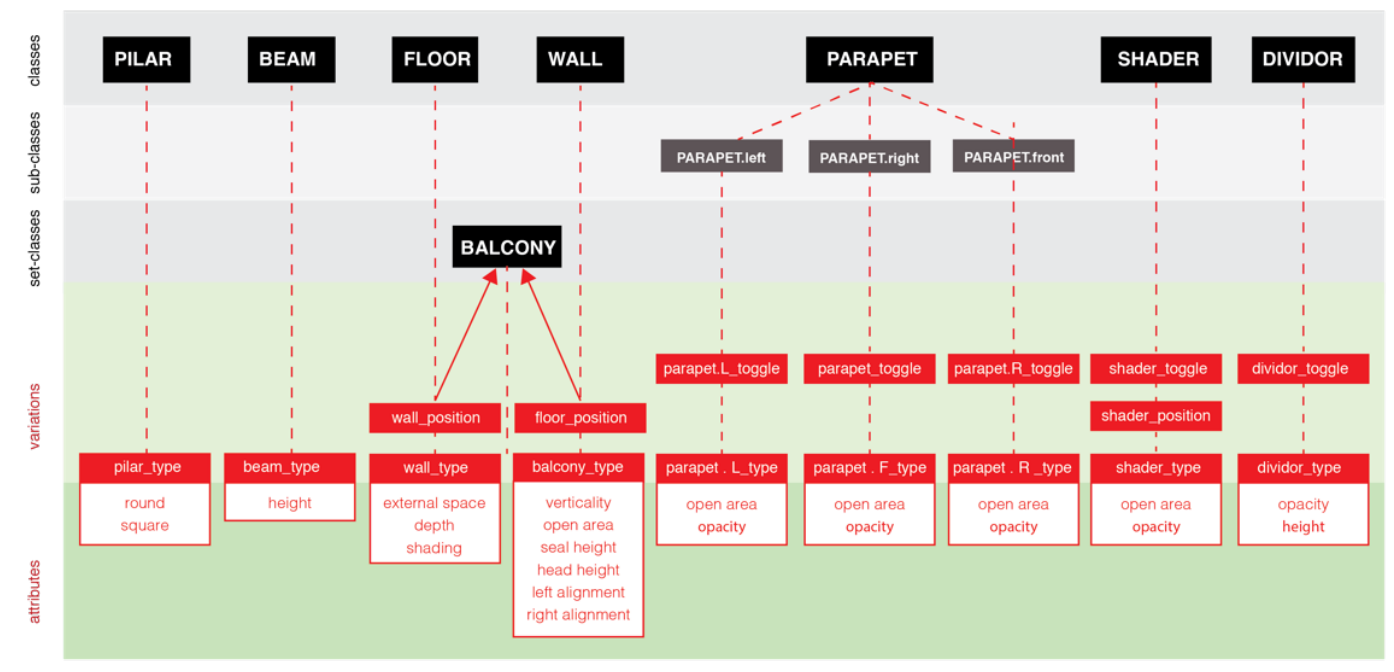

A organização do componente lógico do Supergrid exigiu a criação de um glossário, elaborado no idioma inglês, que inclui os termos pertinentes ao sistema geométrico da malha (module, cell, interstice, address), ao sistema classificatório de elementos (class, sub-class, set, type, library, attribute, etc.), às classes de elementos (wall, shader, parapet) e às variações aplicadas às diferentes classes (parapet_toggle, wall_position e wall_type).

\section{Elementos e regras de relações formais.}

Assim como ocorre nas Gramáticas da Forma, o sistema descrito aqui é estruturado como uma espécie de linguagem, contendo um conjunto de elementos e regras formais que guiam as relações entre estes elementos. No caso do Supergrid, a base para a construção desta gramática são as vertentes racionalistas da modernidade arquitetônica. Em especial interessa exemplares que usem a grelha ortogonal como sistema de organização geométrica na fachada e explorem as possibilidades sintáticas das estruturas independentes de concreto armado (avanço e recuo de lajes em relação à linha dos pilares, supressão das vigas nos pavimentos, uso de planos horizontais e verticais como elementos de fachada). 0 sistema é capaz de acolher elementos que derivam de distintas procedências no campo da arquitetura erudita do século XX. As referências iniciais provêm de projetos exemplares de nomes notáveis do movimento moderno brasileiro (MMM Roberto, Lucio Costa, Rino Levi).

Figura 7. Coleta de elementos. Modelagem de trechos de fachadas de projetos de autoria do escritório MMM Roberto.

Fonte: Autor.
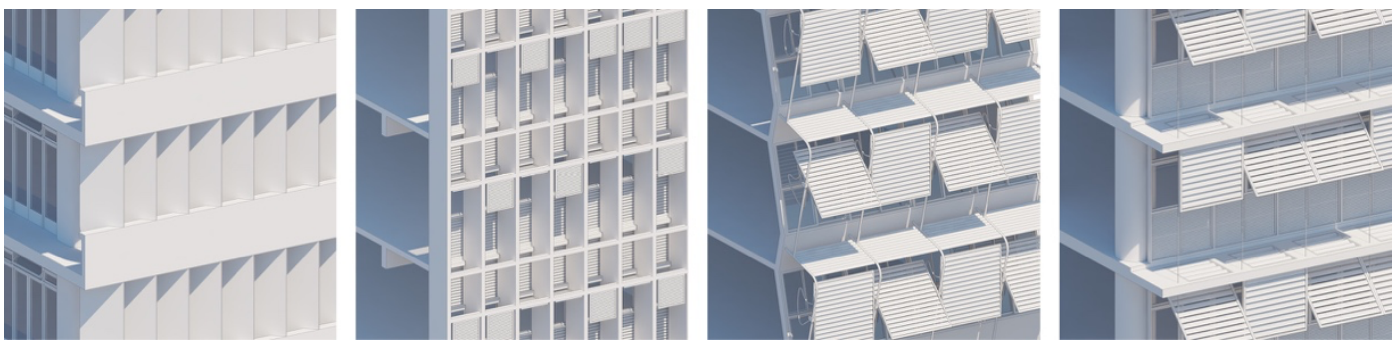
No entanto, por ser pautado por regras formais tão recorrentes, o corpus capaz de alimentar o sistema poderia incluir desde o racionalismo italiano e a arquitetura milanesa do pós-guerra (Giuseppe Terragni, Ignazio Gardella, Asnago e Vender, Luigi Caccia Dominioni), a práticas contemporâneas que se destacam pela elementaridade formal, tanto no Brasil (Nitsche Arquitetos, Andrade Morettin) quanto no exterior (Lacaton \& Vassal, Bruther, Studio Muoto, Arno Brandlhuber). Além disso, não está fora de questão acolher arranjos identificados nas construções ordinárias das periferias brasileiras onde prevaleça o uso de elementos e configurações formais compatíveis com o sistema.

\section{COMPONENTE CONTROLE}

A definição do componente controle no Supergrid implica estabelecer como as variações serão governadas. Estritamente, trata-se do modo empregado para preencher as 17 listas de valores atribuídas a cada célula ou interstício para definir a seleção de tipos de elementos, sua posição em relação à fachada ou a sua supressão em determinado trecho. Algumas destas possuem restrições automáticas embutidas no programa visando evitar combinações consideradas equivocadas (por exemplo, se uma parede avança para fora do limite da fachada, as lajes abaixo e acima também avançam, automaticamente).
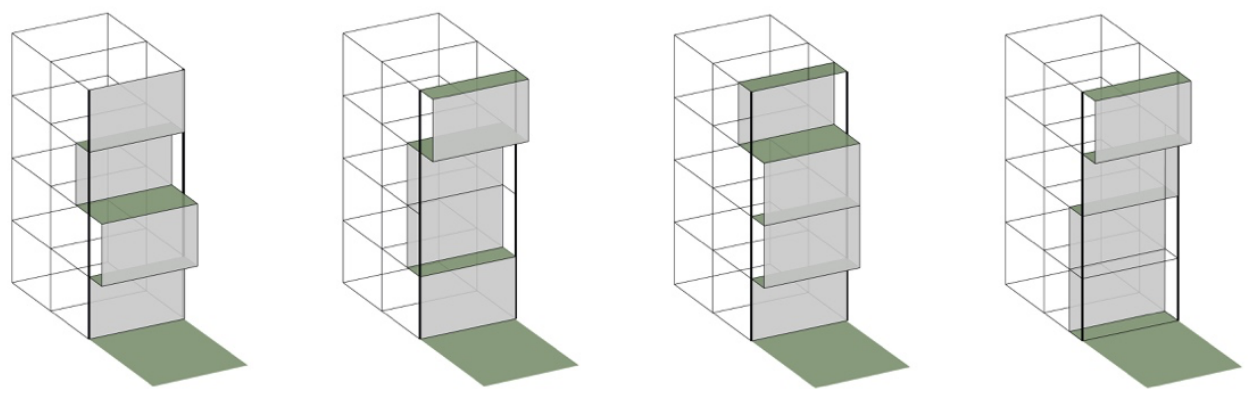

Figura 8. Testes da programação condicional vinculando a posição das lajes com 0 avanço e 0 recuo dos planos de fechamento.

Fonte: Autor.

Figura 9. Modalidades de controle (da esquerda para a direita): humano; randômico; filtrada randômica; filtrada randômica guiada.

Fonte: Autor.

\section{EM BUSCA DE UM CONTROLADOR SEMÂNTICO}

O desenvolvimento do módulo controle possibilitou uma reflexão sobre como os modos de escolha das variações poderiam colaborar com o propósito pedagógico do sistema. Cabe lembrar que o Supergrid foi concebido para ser operado por professores na confecção de 
material didático na forma de uma espécie de catálogo. Neste caso, a questão é a de organização e apresentação desse catálogo. Além disso, tendo em vista a possibilidade de os estudantes operarem o Supergrid como parte de uma experiência pedagógica, se torna premente a questão de como ofertar o manejo das variações. Tais questões sem dúvida, foram consideradas tendo em vista uma intenção pedagógica: a de tratar as variações formais a partir do seu sentido arquitetônico, e não apenas a partir de suas características exclusivamente numéricas ou geométricas. Dito de outra maneira, o desenvolvimento do controlador tinha por objetivo fortalecer a compreensão das implicações semânticas das variações sintáticas. Daí a designação "controlador semântico" adotada nesta pesquisa.

Pode-se ilustrar esta intenção da seguinte maneira: as variações poderiam ter sido organizadas na forma de um gradiente numérico: panos de fechamento ordenados do mais aberto ao mais fechado; a posição dos panos de fechamento do mais recuado ao mais avançado, e assim por diante. Essa organização parece efetiva para explicitar os efeitos sintáticos do manejo de cada operação formal separadamente, mas o que comunicaria a respeito das implicações arquitetônicas destas variações?

As diferentes modalidades desenvolvidas foram consideradas e avaliadas justamente sob a perspectiva da sua potencialidade em destacar o sentido semântico das variações formais no âmbito da fachada.

Entendeu-se que no modo randômico, uma vez que se abre mão da interferência no sistema sujeitando as variações à total aleatoriedade (ainda que dentro dos limites estabelecidos pelo programa), prevalece a ausência de critérios acerca da composição do modelo. 0 resultado é uma organização algo caótica, talvez dotada de forte expressividade visual, mas pouco eficaz na sua capacidade de prover um entendimento acerca das implicações arquitetônicas das variações formais.

No modo de controle humano, por outro lado, a ausência de qualquer automação, além de tornar o processo mais lento, também oferta aos usuários o arbítrio sobre a seleção das variações, com as vantagens e desvantagens que as escolhas subjetivas podem implicar. Neste caso, o desenho do controlador não favorece nenhuma ordem em particular, mas favorece uma exploração criativa e livre (consideradas as limitações embutidas no código do sistema).

Um caminho intermediário está no uso da filtragem, talvez uma solução mais profícua para avançar na construção do controlador semântico. Nesta modalidade os usuários exercem uma ação indireta sobre a seleção de variações ao estabelecer parâmetros relacionados com atributos dos elementos. A organização do modelo / catálogo poderia ser exercida por meio do manejo dos filtros e não pela escolha direta dos elementos. As modalidades com filtros estabelecem um modo de governar o algoritmo que permite operar por meio de critérios arquitetônicos, ainda que qualitativos. Portanto possibilitam um tipo de controle com potencial para estabelecer relações entre as alterações formais (sintaxe) e seu sentido no projeto (semântica).

Para isso, entretanto, seria necessário explicitar tais relações no desenho do controlador: o valor numérico de um filtro deveria corresponder a uma expressão semântica relacionada com uma questão arquitetônica. Abertura de grandes proporções = iluminação abundante; presença do elemento brise $=$ proteção solar.

Um breve ensaio envolvendo a construção de uma nova estrutura lógica para o controlador foi realizado tendo em vista estas ambições. Constatou-se, no entanto, que não é tão simples estabelecer relações diretas entre critérios arquitetônicos, filtros e as variações que eles comandam. Um problema recorrente ocorre quando um mesmo filtro está ligado a diferentes questões endereçadas pela fachada. Por exemplo, um filtro que define a extensão de uma varanda pode ter impacto no potencial de uso, na proteção solar e na expressão de 
profundidade no plano da fachada. Daí a dificuldade de se definir uma única expressão semântica $\neg$ que defina este filtro. Além disso, em muitos casos é necessário mobilizar diversos filtros, relativos a diferentes elementos, para que determinada intenção se efetive. Um exemplo é o potencial de uso da varanda, que depende tanto da sua profundidade quanto da presença de aberturas no plano da fachada que conectem com o espaço interior. Outro exemplo é a busca por proteção solar, que pode ser atingida por uma combinação entre diversos filtros: um que determine a profundidade da varanda, outro que habilite proteções laterais e outro que introduza elementos de proteção externos ao plano de fechamento (toldos ou brises, por exemplo). Finalmente, há a possibilidade de lidar com critérios contraditórios (uma situação comum em projeto que precisa ser endereçada pelo catálogo do Supergrid). Por exemplo, a demanda por vistas em direção ao exterior e a demanda por proteção ao sol poente costumam suscitar respostas contraditórias: aberturas generosas que favoreçam a visão, por um lado, e elementos de proteção que obstruem a vista, por outro. São casos específicos que exigem algum tipo de mitigação.

Numa avaliação crítica desse ensaio compreendeu-se que os filtros não deveriam ser considerados de maneira independente, mas sim de maneira associada, tendo em vista correlações entre múltiplos critérios arquitetônicos, os filtros disponíveis no sistema e as variantes que eles operam. Mais significativamente, compreendeu-se que que para estabelecer tais correlações era necessário recorrer a soluções conhecidas entre as referências de projeto empregadas para construir as bibliotecas de elementos do Supergrid, onde diferentes elementos atuam de modo associado para produzir uma resposta arquitetônica a uma determinada situação.

O que será apresentado a seguir é o desenho conceitual de uma nova modalidade de controle baseada nesta constatação. Apelidada de "controle por sintagma", esta reorganização do controlador vincula diferentes filtros a partir de padrões de combinação de elementos, tendo por base os precedentes arquitetônicos pertinentes à linguagem do sistema.

\section{CONTROLE POR SINTAGMA}

O novo modo de controle das variações se baseia nas associações entre as diferentes variáveis, isto é, na coparticipação de diferentes tipos de elementos e na definição da posição relativa entre eles. A aplicação dessas variações seria guiada pela atuação concomitante de distintos filtros, cujos valores estariam também associados, não podendo ser controlados diretamente e de maneira independente, mas sim a partir da escolha de combinações pré-definidas - algo próximo dos combos nos cardápios dos serviços de comida.

A noção de "controle por sintagma" vem da apropriação de uma figura da linguística - o sintagma - que designa justamente um conjunto de palavras organizadas segundo regras sintáticas (CARVALHO, 2003). A opção por esta designação se dá justamente por se tratar de um termo da gramática usado em referência a um agrupamento de palavras que não é aleatório, mas que se baseia em uma estrutura relacional que, guiada pelas regras da língua, é capaz de produzir sentido. No Supergrid o controle por sintagma pretende possibilitar que a seleção das variações ocorra a partir de conjuntos de elementos que possuem relações sintáticas coerentes e que respondam de maneira conjunta a certo tipo de situação de projeto.

\section{LINGUAGEM DOS PADRÕES}

Em grande medida o novo modo de controle recorre à lógica da Linguagem dos Padrões, célebre sistema de projeto concebido por Christopher Alexander et al. (1977). Um padrão pode ser entendido como uma solução de projeto presente em determinada cultura, capaz de ser 
transformada e aplicada em casos específicos. A constituição de um padrão implica identificar e reconhecer soluções já experimentadas e aprimoradas ao longo do tempo como respostas a problemas que são recorrentes no ambiente construído. É fundamental que os padrões sejam descritos em termos genéricos, o que os torna mais flexíveis e aptos para adaptação.

Enquanto um modo de organizar conhecimento, a Linguagem dos Padrões apesenta duas características que são particularmente relevantes para a nova modalidade de controle do Supergrid. A primeira é que os padrões são apresentados não apenas como soluções arquitetônicas, mas como situações de vivência. Configurações formais e espaciais aparecem vinculadas aos acontecimentos que eles ajudaram a instaurar. Nesta perspectiva um padrão pode ser entendido não apenas como uma solução arquitetônica, mas também como a definição do problema que ela é capaz de resolver. A segunda característica é que os padrões, em sua maioria, dependem de um conjunto de recursos, da mobilização de diferentes elementos que conseguem produzir determinada situação porque se relacionam entre si de determinada maneira. Mais do que um conjunto de partes que se encaixam, cada padrão deve ser compreendido com um "todo", uma unidade cuja coerência depende da sua potencialidade de engendrar situações arquitetônicas. Não há uma prescrição estrita acerca da forma ou atributos específicos dos elementos individuais que compões o padrão: a única exigência é que sejam coerentes com o efeito pretendido.

\section{SINTAGMAS}

A proposta de reorganizar o controlador por meio da vinculação de diferentes filtros e da combinação de elementos se alimenta em parte da lógica subjacente ao uso de padrões como sistema de projeto. 0 problema do tratamento independente das variáveis e a dificuldade de um conjunto de filtros a um conjunto de critérios de projeto foi contornado com a aproximação de precedentes arquitetônicos onde diversos elementos atuam em conjunto criando respostas coerentes para problemas de projeto com demandas múltiplas e por vezes conflitantes.

o exemplo mencionado anteriormente, onde havia conflito entre a demanda de vista e demanda de proteção solar, encontra um paralelo em casos célebres da arquitetura moderna brasileira, os projetos de Lucio Costa para o parque Guinle, em especial os edifícios Bristol (1950) e Caledônia (1954). A implantação favorecida pelas condições do terreno fez com que as fachadas principais - das salas e dormitórios - fossem orientadas para oeste, com vista para o parque e para a mansão dos Guinle no topo do morro. Se descrita nos termos do Supergrid, a solução adotada por Costa incluiria: ausência de vigas, avanço da laje, fechamentos com panos de vidro do chão ao teto (recuados nos dormitórios e avançados na sala), divisórias separando as varandas do quarto e da sala, elementos de proteção solar (brises nos dormitórios, cobogós nas salas). A proteção solar, é importante notar, possui aberturas quadradas nos cobogós e uma interrupção dos brises.

Essa combinação de elementos atua de maneira orquestrada para prover respostas a uma situação de projeto com múltiplas demandas: espaço de permanência, proteção solar, vista, resguardo, privacidade, unidade visual do conjunto (alinhamento, repetição e ritmo). Segundo a nova modalidade, esse grupo de elementos pode ser entendido com um sintagma. Seu sentido depende da presença de todos estes elementos atuando em conjunto e nessa relação de posição.

No entanto, é possível substituir elementos do sintagma por outros equivalentes, mudando o seu sentido sem alterar sua estrutura (Figura 10). É o que ocorre quando o elemento cobogó é substituído por brises, ou quando o avanço do pano de vidro na sala é substituído por um recuo no dormitório, mudando a profundidade da varanda. Segundo a linguística moderna de 
Saussure (CARVALHO, 2003), essa é uma alteração de "seleção" e abre possibilidades interessantes para o controlador.

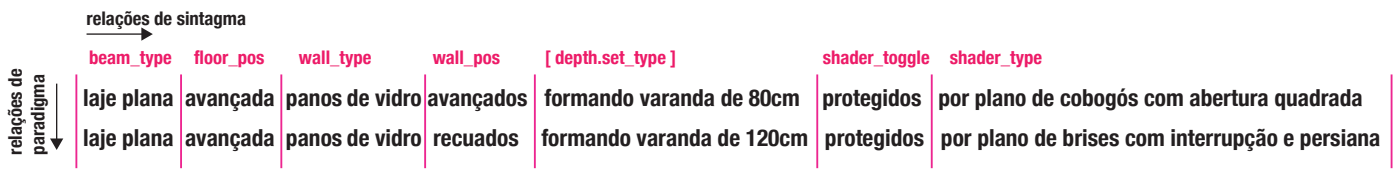

A hipótese do "controle por sintagma" envolve a construções de padrões, conjuntos que associam classes de elementos e relações de posição. A atribuição das variações a uma determinada célula da fachada se daria por meio da eleição de um sintagma que, por sua vez, mobilizaria certos filtros para controlar as variações. A escolha do sintagma pode se dar por meio de palavras-chave que resumam seu sentido - uma espécie de alias - ou de diagramas visuais que expressem as relações entre os seus elementos - uma espécie de ícone.

Por exemplo, a fachada dos edifícios Bristol e Caledônia corresponderiam a um sintagma padrão, talvez nomeado "varanda" oeste protegida com vista". Ao atribuir este sintagma para uma célula, um conjunto de filtros seria mobilizado, garantindo certas relações formais (distância entre plano de proteção e plano de fechamento viabilizando a criação de uma varanda) e certas qualidade dos elementos (o plano vazado seria fechado o suficiente para proteger do sol poente, mas possibilitaria eventual acesso à vista). A partir destes filtros, a geração de seleção de combinações de elementos (aleatória ou manual) se veria restrita às limitações impostas pela estrutura do sintagma. Assim, o plano de proteção poderia ser alterado de "cobogó" para "toldo retrátil", ou para "painel pivotante", por exemplo. Nesta perspectiva é fundamental que o Supergrid conte com bibliotecas ricas em variações de tipos de elementos.

Além disso, o sintagma é, ele próprio composto e pode ser simplificado ou tornado mais complexo. O nome "varanda oeste protegida com vista" contém diversos conjuntos de elementos que podem ser eliminados, alterando o conjunto filtros mobilizados na seleção. Assim, poderia haver uma simples "varanda oeste protegida", eliminando a necessidade das interrupções no plano de proteção, ou "varanda oeste" suprimindo o plano de proteção, mas mantendo a configuração de varanda.

A construção dos sintagmas disponíveis no sistema tem base no exame de precedentes considerados pertinentes à gramática do Supergrid. 0 conjunto preliminar, pode ser exemplificado por sintagmas como "parede com janela quadrada", "parede com janela horizontal", "parede com janela horizontal profunda", "parede com janela horizontal alta", "parede com janela horizontal com proteção móvel", "pele de vidro", "pele de vidro protegida com proteção fixa", "varanda", "varanda recuada", "varanda avançada", etc.

\section{CONSIDERAÇÕES FINAIS}

A hipótese de reorganização da estrutura do controlador do Supergrid tem à sua frente desafios relativos à sua implementação. Do ponto de vista computacional irá demandar a elaboração de mais uma camada de controle, totalizando três (sintagmas, filtros e variações). A construção de uma estrutura lógica mais sofisticada será necessária, provavelmente exigindo que se adote programação em Python dentro do ambiente Grasshopper. Neste processo será necessário percorrer as referências coletadas durante a elaboração da gramática para organizar de modo sistemático os conjuntos de sintagmas que comporão essa nova camada de
Figura 10. Ilustração de estrutura sintagmática segundo gramática de Saussure.

Fonte:

Autor. 
controle. Além disso, será preciso desenvolver uma interface amigável para o manejo do sistema se persistir a intenção de ofertar aos estudantes a possibilidade do controle do sistema.

Apesar destes desafios, entende-se que a hipótese de reorganização do módulo de controle é promissora pois parece endereçar aspectos chave das

contingências de uso do algoritmo, em particular o seu propósito pedagógico de estabelecer uma ligação entre as variações sintáticas e a dimensão semântica da forma arquitetônica. Por um lado, a adoção de parte da lógica da Linguagem dos Padrões - em especial a recuperação de precedentes e o uso dos elementos associados - permite uma aproximação entre as operações formais abstratas do ambiente digital e o universo da cultura arquitetônica representada pela tradição da arquitetura moderna brasileira. Por outro lado, a possibilidade de expressar o controle das variações por meio dos sintagmas, cuja expressão pode ser tanto visual quanto verbal, reforça o sentido semântico da forma. Nomear os elementos e os conjuntos a partir de um vocabulário conhecido $\urcorner-$ proteção, resguardo, vista, varanda, janela, passagem - sem dúvida contribuem para deslocar as formas do seu estado de geometria para uma posição mais próxima daquilo que se conhece por ambiente construído e por vida cotidiana.

\section{Referências Bibliográficas}

ALEXANDER, C.; ISHIKAWA, S.; SILERVSTEIN, M. A Pattern Language. Towns. Buildings. Construction. Oxford University Press, 1977.

BEIRÃO. J., DUARTE, J. Urban Grammars: Towards Flexible Urban Design. Proceedings... 23rd ECAADE CONFERENCE, 2005, Lisboa. Conference Proceedings: Lisboa, 23 ${ }^{\text {rd }}$ eECAADe Conference [ ISBN 0-9541183-3-2] Lisboa, pp. 491-500, 2005. Disponível em: http://papers.cumincad.org/cgi-bin/works/Show?2005 491. Acesso em: 18 jan, 2020.

BEIRÃO, J. CltyMaker: Designing Grammars for Urban Design. 2012. Tese. Ph.D. Thesis, TU Delft, 2012.

CARVALHO, C. Para Compreender Saussurre. Petrópolis: Vozes, 2003. 154 p. 15. ed.

DUARTE, J.P. Customizing Mass Housing: A Discursive Grammar for Siza's Malagueira houses. 2001. PhD Thesis. Massachusetts Institute of Technology, 2001.

DE KLERK, R.; BEIRÃO, J. Ontologies and Shape Grammars: A Relational Overview Towards Semantic Design Systems. Proceeding... 34th eCAADe Conference, Oulu, Finlandia. Conference Proceedings: Oulu, Finlandia, Vol: 2, 2016.

ENGEL, P; ESKINAZI, M. Por Uma Arquitetura Elementar. In: Revista Thesis. Anparq, 3, pp. 54-76, 2016.

ENGEL, P. Controlling Design Variations Designing a Semantic Controller For a Generative System. Proceedings... Architecture in the Age of the 4th Industrial Revolution - 37th eCAADe and 23rd SIGraDi. Conference Proceedings: Porto, vol.7, eCAADe SIGraDi, 2019. DOI: 10.5151/proceedings-

ecaadesigradi2019_191

GRUBER, T. R. Toward principles for the design of ontologies used for knowledge sharing? In: International Journal of Human-Computer Studies, 43, pp. 907-928, 1995.

GARCIA, S. (2016) Classification of Shape Grammars. Proceedings... Design Computing and Cognition, 16, 2016. Conference Proceedings: J. S. Gero. (Ed.) pp. 243-262, 2016

KOWALSKI, R. Algorithm = Logic + Control. Communications of the ACM, Vol. 22, No. 7, Jul. p. 424-436, 1979.

LOVE, Timothy. Kit-of-Parts Conceptualism. Harvard Design Magazine, No.19, 2003. Disponível em: http://www.harvarddesignmagazine.org/issues/19/kit-of-parts-conceptualism-abstracting-architecture-in-theamerican-academy. Acessado em: 2 maio, 2019. 
LIN, Chieh-Jen. (2015). Design Criteria Modelling. Proceedings... Conference on Computer-Aided Architectural Design Research in Asia, 20, Daegu, Coréia. Conference Proceedings: Caadria, 2015.

STINY, G. (1993) Emergence and Continuity in Shape Grammars. Proceedings... CAAD Futures '93. Conference Proceedings. Pittsburgh, EUA, p. 37-54, 1993.

STOUFFS, R.; HOU, D. An algorithmic design grammar for problem solving. Automation in Construction. Vol. 94, out. 2018. DOI: 10.1016/j.autcon.2018.07.013

STOUFFS, R. Where Associative And Rule-Based Approaches Meet A Shape Grammar Plug-in for Grasshopper. Proceedings... CAADRIA Conference, 23, 2018, Beijing. Conference proceedings: 23rd CAADRIA Conference. Disponível em: https://www.researchgate.net/publication/325853494. Acessado em: 3 mai. 2019.
Pedro Engel pedroengel@fau.ufrj.br 